\title{
COMPARISON OF THE CIRCULATORY RESPONSE TO UPRIGHT EXERCISE IN 25 "NORMAL" MEN AND 9 DISTANCE RUNNERS*
}

\author{
BY \\ J. S. HANSON† AND B. S. TABAKIN \\ From the Cardiopulmonary Laboratory, Department of Medicine, University of Vermont College of Medicine, Mary \\ Fletcher Hospital, Burlington, Vermont, U.S.A.
}

Received April 27, 1964

Although "of essential physiological interest” (Åstrand, 1956), studies of physical performance comparing the circulatory and ventilatory responses to exercise of normal men and athletes have been regrettably few in number. Likewise, investigations of the effects of physical training on performance have been reported only infrequently. Inconsistencies in published results may be accounted for by several factors, including study of only 2 or 3 subjects, employment of too few work loads to delineate fully the range from minimal to maximal exercise, and use of recumbent rather than upright exercise position. Freedman et al. (1955) studied the supine cardiac output response of 3 cross-country runners at three or four levels of exercise, the highest oxygen utilizations being $2.01 . / \mathrm{min}$. Of the 3 subjects, 2 were studied before and after training. Bevegård, Holmgren, and Jonsson (1963) reported circulatory studies in 8 cyclists exercising in both supine and sitting position, but only two levels of work were employed. These results were compared with two earlier studies in non-athletic normal subjects (Bevegård, Holmgren, and Jonsson, 1960; Holmgren, Jonsson, and Sjöstrand, 1960a), but the work loads in these two latter groups were not strictly comparable with those of the athletes. A review of these findings is included in Bevegard's thesis (1962). Hæmodynamics during graded supine exercise in 9 athletes, 13 men, and 4 women have been reported by Musshoff, Reindell, and Klepzig (1959a), and Musshoff et al. (1959b). Holmgren (1956) studied 35 well-trained cyclists to find the effect of exercise on arterial, venous, and œsophageal pressures, while a later report by the same author (Holmgren et al., 1960b) discussed the effects of training on heart rate, work capacity, and other parameters. Prolonged severe treadmill exercise was employed by Cobb and Johnson (1963) in studying 14 sedentary normal subjects and 10 athletes. Wang, Marshall, and Shepherd (1960) reported the circulatory effects of posture change and graded exercise in 3 athletes, while an abstract by the same author (Wang et al., 1961) compared the cardiac response to exercise in 5 unconditioned men and 5 athletes. An as yet unpublished investigation by the same group (Wang et al., 1965) will present the effects of a systematic conditioning programme on the cardiovascular function of 7 sedentary college men. Many of Åstrand's publications (1952, 1956) deal primarily with the ventilatory and metabolic responses to exercise in normal subjects and athletes, and Jongbloed (1962) has discussed the effects of training on oxygen utilization and carbon dioxide elimination in championship skaters. Fourteen sedentary subjects were studied by Frick, Konttinen, and Sarajas (1963) before and after two months of army basic training conditioning.

The present study is concerned with a comparison of the circulatory and ventilatory responses to graded upright exercise in 25 "normal" young men and 9 cross-country runners. An extension of

* This study was supported by USPHS Research Grant HE-06121-02 and -03 of the National Heart Institute. † Recipient of USPHS Career Research Program Award (1-K3-HE-7248) of the National Heart Institute, Bethesda, Maryland. 
TABLE I

ANTHROPOMETRIC DATA for Groups N AND R

\begin{tabular}{|c|c|c|c|c|}
\hline Subject & Age & Height $(\mathrm{cm})$. & Weight (kg.) & $\operatorname{BSA}\left(\mathrm{m} .{ }^{2}\right)^{*}$ \\
\hline $\begin{array}{r}\text { Group } N \\
1 \\
2 \\
3 \\
4 \\
5 \\
5 \\
6 \\
7 \\
8 \\
9 \\
10 \\
11 \\
12 \\
13 \\
14 \\
15 \\
16 \\
17 \\
18 \\
19 \\
20 \\
21 \\
22 \\
23 \\
24 \\
25\end{array}$ & $\begin{array}{l}23 \\
24 \\
21 \\
26 \\
21 \\
26 \\
22 \\
20 \\
23 \\
24 \\
25 \\
26 \\
22 \\
27 \\
22 \\
22 \\
23 \\
26 \\
24 \\
23 \\
28 \\
24 \\
20 \\
22 \\
20\end{array}$ & $\begin{array}{l}162 \\
175 \\
185 \\
145 \\
183 \\
185 \\
163 \\
178 \\
175 \\
178 \\
177 \\
183 \\
173 \\
183 \\
171 \\
175 \\
178 \\
179 \\
181 \\
178 \\
182 \\
177 \\
178 \\
175 \\
188\end{array}$ & $\begin{array}{l}77 \\
85 \\
84 \\
68 \\
69 \\
83 \\
64 \\
70 \\
72 \\
85 \\
77 \\
77 \\
72 \\
76 \\
58 \\
73 \\
79 \\
93 \\
87 \\
71 \\
73 \\
94 \\
94 \\
70 \\
80\end{array}$ & $\begin{array}{l}1.82 \\
2.00 \\
2.08 \\
1.59 \\
1.90 \\
2.07 \\
1.68 \\
1.87 \\
1.86 \\
2.03 \\
1.93 \\
2.00 \\
1.81 \\
1.98 \\
1.68 \\
1.88 \\
1.97 \\
2.12 \\
2.08 \\
1.88 \\
1.93 \\
2.10 \\
1.87 \\
1.85 \\
2.05\end{array}$ \\
\hline Mean & 23 & 176 & 77 & 1.92 \\
\hline $\begin{array}{l}1 \\
2 \\
3 \\
4 \\
5 \\
6 \\
7 \\
8 \\
9\end{array}$ & $\begin{array}{l}21 \\
24 \\
20 \\
21 \\
20 \\
19 \\
24 \\
18 \\
18\end{array}$ & $\begin{array}{l}182 \\
176 \\
178 \\
169 \\
188 \\
180 \\
176 \\
155 \\
176\end{array}$ & $\begin{array}{l}76 \\
71 \\
70 \\
78 \\
80 \\
71 \\
71 \\
66 \\
74\end{array}$ & $\begin{array}{l}1.96 \\
1.87 \\
1.87 \\
1.95 \\
2.05 \\
1.90 \\
1.87 \\
1.67 \\
1.90\end{array}$ \\
\hline Mean & 21 & 176 & 73 & 1.89 \\
\hline
\end{tabular}

* Body surface area.

this report (Tabakin, Hanson, and Levy, 1965) deals with the effects on these responses of a 3-month period of intensive training in a different group of 9 cross-country runners.

\section{SubJECTS AND ḾETHODS}

Group $\mathrm{N}$ consisted of 25 normal male undergraduates and medical students, 20-29 years of age, who served as subjects for a previous study (Tabakin et al., 1964). The men participated in the project on a voluntary basis, and though a fee was paid for participation, payment was not dependent on successful completion of any previously-determined amount of work. Selection of Group $\mathbf{N}$ with regard to previous athletic participation and current sports activities was entirely random. Only 3 of the 25 subjects performed any regular physical exercise, and the group therefore represented a somewhat disturbingly sedentary crosssection of our university undergraduate and postgraduate population.

Group $\mathrm{R}$ was composed of 9 members of the University of Vermont varsity cross-country track team which compiled a 4-3 win-loss intercollegiate record in 1962. Though the mean age of this group was slightly lower than that of Group N, it was not significantly so. Mean body surface area was $1.92 \mathrm{~m} .{ }^{2}$ for Group N and $1.89 \mathrm{~m} .{ }^{2}$ in Group R. Anthropometric data for both groups are presented in Table I. Members of 
Group R, after setting-up exercises and organized pre-run calisthenics, ran four to five miles every afternoon and participated in intercollegiate meets on the average once a week for the entire three-month track season.

No attempt was made in this comparative study to correlate differences in the two groups with regard to dietary habits, smoking, hours of sleep at night, or other such poorly-controlled factors. The primary difference in the two groups for the purpose of this investigation was that of physical activity and training.

Circulatory and respiratory variables were measured by methods previously reported in detail from this laboratory (Tabakin et al., 1964; Hanson and Tabakin, 1964). In brief, subjects were studied recumbent at rest, standing at rest, and while walking on the level motor-driven treadmill and at elevations of $4^{\circ}, 8^{\circ}, 12^{\circ}$, and $14^{\circ}$. Estimation of cardiac output was made by a single-injection, continuous arterial sampling method employing a Waters Model 250-A monochromatic densitometer* modified for zero suppression and correction of background dye build-up during repeated injections of cardiogreen $\dagger$ indicator. For each subject a 3-point calibration curve was recorded using cardiogreen concentrations of $6.0,3.0$, and $1.5 \mathrm{mg} . / 1$. in the subject's own arterial blood. Without exception, these calibrations were linear through the above three points and origin.

Heart rate was monitored by FM telemetry $\ddagger$ of the electrocardiogram. Expired gas was collected in Douglas bags, measured and analysed for oxygen and carbon dioxide in the Beckman Model E-2 and LB-1 analysers respectively. Intra-arterial blood pressure recordings were made with Statham P23Db strain gauges. Mean arterial pressure was obtained by the usual method of capacitor attenuation of pressure frequency response. All recordings were made with a rapidly-developing Electronics for Medicine DR-8 photographic recorder. Left ventricular work index was calculated as the product of cardiac index, mean blood pressure in $\mathrm{mm}$. $\mathrm{Hg} \times 13.6 \div 1000$, expressed as $\mathrm{kg} . \mathrm{m} . / \mathrm{min} . / \mathrm{m} .{ }^{2}$ Left ventricular stroke work index was calculated in the same manner using stroke index and the result was expressed as $\mathrm{g} . / \mathrm{m} .{ }^{2}$

Several days before the determinations each subject was acquainted with the laboratory, instrumentation, and protocol of the investigation, and taught to walk on the treadmill. A concerted effort was made by all laboratory personnel to reduce subject apprehension to a minimum.

During the exercise studies the subjects were allowed to rest after each walk until heart rate had returned to or very near to the resting recumbent value. Because several of the untrained subjects early in the investigation had become hypotensive and faint after standing motionless for two to three minutes, the resting upright measurements were subsequently made after completion of all exercise. The subjects were therefore allowed to rest recumbent for 15-25 minutes after the last exercise period before the final standing studies.

All data for each subject were key-punched on IBM cards. Several programmes were written for the IBM 1620 Data Processing System for statistical analysis. Means, standard errors, and standard deviations of the means were calculated for all variables, and correlation coefficients and regression equations for appropriate comparison of data were obtained. Standard errors of the estimate were calculated for regression lines. Statistical significance of differences was determined by $t$ test at $n-2$ degrees of freedom, differences of means, and variance analysis.

\section{RESULTS}

Tabular presentation of results is given in Table II. It can be seen that of the 14 parameters compared in Groups $\mathbf{R}$ and $\mathbf{N}$, significant differences were seen in surprisingly few instances. Of major importance is the fact that the work loads at each level of exercise were closely matched for both groups and were always insignificantly different. Heart rate at rest, both recumbent and standing, as well as at all levels of exercise was lower in Group $\mathbf{R}$. The differences in heart rate and significance of these differences became progressively greater to a highly significant degree with increasing work loads. Cardiac output was consistently lower in the athletes but not significantly so. Level walking was associated with a mean cardiac output for Group $\mathbf{R}$ which was possibly significantly lower $(p<0.05)$ than that of Group N. As intensity of exercise increased, differences in the two groups decreased. Relative differences in cardiac index were even less marked than those in cardiac output.

Reflecting the athletes' lower heart rate at all exercise levels, stroke volume was uniformly higher in Group $R$ though not significantly so except possibly at the $12^{\circ}$ treadmill inclination. Standing at

* Waters Corporation, Rochester, Minnesota.

$\uparrow$ Hynson, Westcott, and Dunning, Baltimore, Maryland.

† RKG 100, Telemedics, Inc., Southampton, Pennsylvania. 
TABLE II

Mean Values of all Measurements at Rest and for Each Exercise Level

\begin{tabular}{|c|c|c|c|c|c|c|c|c|c|c|c|c|c|c|c|c|c|}
\hline \multirow{2}{*}{\multicolumn{3}{|c|}{ Exercise level }} & \multirow[t]{2}{*}{ Subjects } & \multirow{2}{*}{$\begin{array}{c}\text { Heart } \\
\text { rate } \\
\text { (beats/ } \\
\text { min.) }\end{array}$} & \multirow{2}{*}{$\begin{array}{l}\text { Cardiac } \\
\text { output } \\
\text { (1./min.) }\end{array}$} & \multirow{2}{*}{$\begin{array}{c}\text { Cardiac } \\
\text { index } \\
(1 . / \mathrm{min} . / \\
\mathrm{m.2}\end{array}$} & \multirow{2}{*}{$\begin{array}{c}\text { Stroke } \\
\text { volume } \\
\text { (ml.) }\end{array}$} & \multirow{2}{*}{$\begin{array}{l}\text { Minute } \\
\text { volume } \\
\text { (1./min.) } \\
\text { BTPS }\end{array}$} & \multirow{2}{*}{$\begin{array}{c}\mathbf{O}_{2} \\
\text { utiliz. } \\
\text { (ml./ } \\
\text { min.) } \\
\text { STPD }\end{array}$} & \multirow{2}{*}{$\underset{\text { elimin. }}{\mathrm{CO}_{2}}$} & \multirow{2}{*}{$\begin{array}{l}\text { Work } \\
\text { load } \\
\text { (kg./ } \\
\text { min.) }\end{array}$} & \multicolumn{3}{|c|}{$\begin{array}{c}\text { Blood pressure } \\
(\mathrm{mm} . \mathbf{H g})\end{array}$} & \multirow{2}{*}{$\begin{array}{c}\text { PVR } \\
\text { (dynes } \\
\text { cm. } \\
\text { sec. }-5 \text { ) }\end{array}$} & \multirow{2}{*}{$\underset{\substack{\text { LVWI } \\
\text { min. } \\
\text { m.2) }}}{\operatorname{mg} . /}$} & \multirow[t]{2}{*}{$\begin{array}{l}\text { LVSWI } \\
\left(\mathrm{g} \cdot / \mathrm{m} .^{2}\right)\end{array}$} \\
\hline & & & & & & & & & & & & syst. & diast. & mean & & & \\
\hline $\begin{array}{l}\text { Level } \\
4^{\circ} \ldots \\
8^{\circ} \ldots \\
12^{\circ}\end{array}$ & ent & rest & $\begin{array}{l}\mathbf{R} \\
\mathbf{N} \\
\mathbf{R} \\
\mathbf{N} \\
\mathbf{R} \\
\mathbf{N} \\
\mathbf{R} \\
\mathbf{N} \\
\mathbf{R} \\
\mathbf{N} \\
\mathbf{R} \\
\mathbf{N} \\
\mathbf{R} \\
\mathbf{N}\end{array}$ & $\begin{array}{r}59 \\
72 \\
74 \\
109 \\
87 \\
107 \\
98 \\
123 \\
113 \\
152 \\
136 \\
168 \\
145 \\
176\end{array}$ & $\begin{array}{r}7 \cdot 36 \\
8 \cdot 03 \\
6 \cdot 25 \\
6 \cdot 73 \\
10 \cdot 81 \\
13 \cdot 31 \\
13 \cdot 57 \\
15 \cdot 51 \\
17 \cdot 53 \\
19 \cdot 47 \\
21 \cdot 23 \\
22 \cdot 57 \\
20 \cdot 90 \\
21 \cdot 55\end{array}$ & $\begin{array}{r}3.89 \\
4.20 \\
3.30 \\
3.50 \\
5.70 \\
6.93 \\
7.18 \\
8.12 \\
9.31 \\
10 \cdot 14 \\
11.13 \\
11.71 \\
11.09 \\
11.09\end{array}$ & $\begin{array}{r}126 \\
112 \\
87 \\
63 \\
125 \\
125 \\
139 \\
127 \\
158 \\
133 \\
159 \\
136 \\
146 \\
122\end{array}$ & $\begin{array}{r}10.37 \\
9.60 \\
11.99 \\
12.21 \\
26.64 \\
24.23 \\
31.40 \\
32.08 \\
40.17 \\
45.87 \\
52.03 \\
59.10 \\
60.19 \\
68.04\end{array}$ & $\begin{array}{r}297 \\
300 \\
396 \\
423 \\
1013 \\
1040 \\
1401 \\
1480 \\
1968 \\
2117 \\
2434 \\
2676 \\
2832 \\
2948\end{array}$ & $\begin{array}{r}255 \\
250 \\
251 \\
285 \\
648 \\
773 \\
905 \\
1172 \\
1256 \\
1710 \\
1779 \\
2228 \\
1972 \\
2406\end{array}$ & $\begin{array}{l}\text { 二 } \\
\text { 二 } \\
\text { - } \\
\overline{408} \\
428 \\
817 \\
856 \\
1225 \\
1290 \\
1429 \\
1501\end{array}$ & $\begin{array}{l}124 \\
124 \\
108 \\
109 \\
133 \\
139 \\
131 \\
140 \\
133 \\
134 \\
138 \\
137 \\
140 \\
132\end{array}$ & $\begin{array}{l}66 \\
67 \\
62 \\
65 \\
54 \\
60 \\
52 \\
57 \\
52 \\
55 \\
60 \\
53 \\
59 \\
49\end{array}$ & $\begin{array}{l}82 \\
82 \\
76 \\
80 \\
81 \\
85 \\
81 \\
83 \\
79 \\
78 \\
82 \\
77 \\
82 \\
75\end{array}$ & $\begin{array}{r}911 \\
849 \\
993 \\
1013 \\
636 \\
536 \\
486 \\
442 \\
376 \\
335 \\
316 \\
283 \\
318 \\
286\end{array}$ & $\begin{array}{r}4.34 \\
4.68 \\
3.41 \\
3.81 \\
6.28 \\
8.01 \\
7.91 \\
9.17 \\
10.00 \\
10.76 \\
12.61 \\
12.26 \\
12.37 \\
11.31\end{array}$ & $\begin{array}{l}74 \cdot 72 \\
64 \cdot 68 \\
47 \cdot 55 \\
35 \cdot 90 \\
72 \cdot 71 \\
75 \cdot 14 \\
81 \cdot 52 \\
74 \cdot 50 \\
90 \cdot 25 \\
73 \cdot 20 \\
93 \cdot 68 \\
74 \cdot 35 \\
85 \cdot 87 \\
65 \cdot 29\end{array}$ \\
\hline
\end{tabular}

$\mathrm{R}=$ runners ( 9 subjects, 62 determinations); $\mathrm{N}=$ normals (25 subjects, 162 determinations); PVR=Peripheral vascular resistance; $L V W I=$ Left ventricular work index; $L V S W I=L e f t$ ventricular stroke work index.

rest, however, the runners had a significantly higher stroke volume than the non-athletes $(\mathrm{p}<0.01)$ and this increased 48 per cent in Group $\mathrm{R}$ with level walking, whereas the response in Group $\mathrm{N}$ was a 100 per cent increase over the standing value (Fig. 1). The difference in the stroke volume response to onset of mild exercise is highly significant $(\mathrm{p}<0.001)$. In considering the over-all changes with exercise in both groups, it should be noted that the runners were able to reach a peak stroke volume which was possibly significantly higher than their resting recumbent value. The same was not true for the normal subjects, and indeed their mean peak exercise stroke volume was only $11 \mathrm{ml}$. higher than that during supine rest. Also, when peak exercise is compared to the lowest degree of exercise, the runners are seen to increase stroke volume 27 per cent above that of level walking, while the normal subjects demonstrated a corresponding increase of only 9 per cent.

Blood pressure response to the entire range of exercise in both groups showed insignificant differences with regard to systolic, diastolic, and mean pressures. Pressure levels at recumbent rest were identical for the two groups, and both demonstrated the same response to standing. Peripheral vascular resistance decreased progressively with increasing work load in the entire material, no significant group variance being noted.

With regard to ventilatory variables, the athletes evidenced generally lower minute volumes of ventilation, and this tendency became more pronounced with more severe exercise. The difference between groups was consistently non-significant, however. The same observations may be made in reference to oxygen utilization, whether calculated from raw data or on a ml./kg. basis. In view of the above it was, therefore, somewhat surprising to find that at all degrees of exercise above level walking Group $\mathbf{R}$ had significantly lower carbon dioxide elimination than Group $\mathbf{N}$.

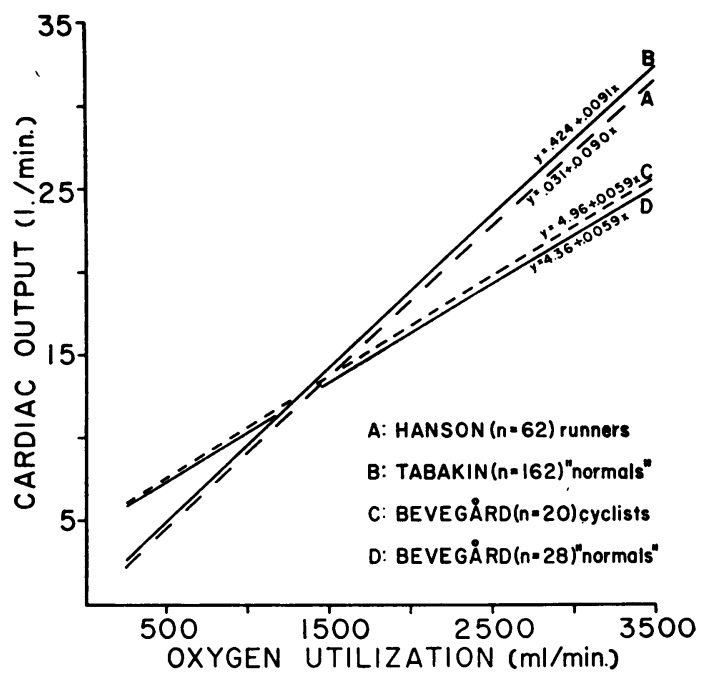

FIG. 1.-Correlation of oxygen utilization and cardiac output for the present study in athletes and nonathletes (lines A and B). Comparison is made with data of Bevegård et al. $(1960,1963)$ in corresponding groups. Regression equations are presented for each group. 
This was especially marked in the mid-range of exercise. When related to body weight (ml./kg.), these variations were also significant.

\section{Discussion}

Lack of significant difference in cardiac output response of Groups $\mathrm{R}$ and $\mathrm{N}$ is illustrated by regression lines A and B respectively in Fig. 1, where oxygen utilization is plotted as an indicator of work severity. It will be noted that there is not a great deal of variation between regression lines A-B and lines C-D, the latter having been calculated for the data of Bevegård et al. $(1960,1963)$ for athletes and normal subjects respectively. The variation in the two series may well be related to differences in the two methods of cardiac output determination employed, since it is a general finding that the values obtained by the dye-dilution technique are 10-12 per cent higher than those employing cardiac catheterization and the Fick principle. Regression lines A and B indicate that a cardiac output increase of $900-910 \mathrm{ml}$. may be expected for each $100 \mathrm{ml}$. increase in oxygen utilization. This figure agrees well with that of Harvey et al. (1962) though the latter was obtained from studies in supine subjects over a low exercise range.

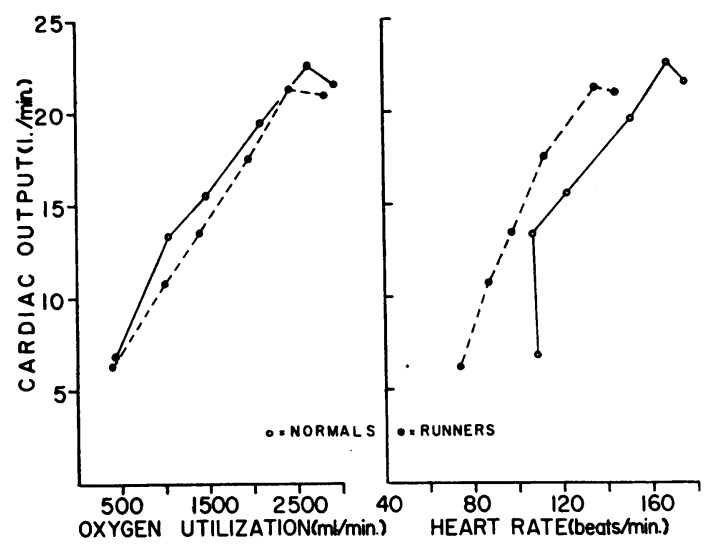

Fig. 2.-Relation of mean values for cardiac output to those for oxygen utilization and heart rate for subjects standing at rest and at five levels of treadmill exercise.

This similarity of cardiac output response in normal subjects and athletes is in agreement with previous reports (Bevegård et al., 1963; Musshoff et al., 1959a; Cobb and Johnson, 1963). Contrary to the findings of Bevegård et al. (1963), the athletes in the present study exhibited a consistently lower cardiac output at rest and at all levels of exercise than did the non-athletes, though the group differences were not statistically significant at any level of exercise (Fig. 2). However, since the data of the present report include five levels of exercise from mild to strenuous, it is difficult to make strict comparisons with any previously published results. During level treadmill walking both groups have almost identical oxygen utilization, but the runners have achieved a lower level of cardiac output $(2.5 \mathrm{l} / \mathrm{min}$. mean difference). This difference diminishes progressively with increasing work loads.

Graphic representation is also presented in Fig. 2 of the relation between cardiac output and heart rate when standing at rest and at each exercise level. It is evident that for any given cardiac output or work load Group R manifests a considerably lower heart rate. This is most marked when standing at rest where the absolute mean difference is 35 beats a minute. Furthermore, this standing heart rate in the athletes represents only a 25 per cent increase above that of resting recumbent, whereas in the normal subjects assumption of the upright position is associated with a 51 per cent increment in resting supine heart rate. The left ventricular work index was similar for both groups recumbent and standing at rest. At the two lowest work levels the non-athletes had indices 28 and 16 per cent higher than the runners, but the values were almost identical at $8^{\circ}$ and $12^{\circ}$ treadmill elevations. Work index at the $14^{\circ}$ level was 9.4 per cent higher in the athletes than in the normal subjects, reflecting a higher mean arterial blood pressure in Group R, since cardiac index was identical in both groups.

It is of interest that the peak work loads in this study $(1429 \mathrm{~kg} . \mathrm{m} . / \mathrm{min}$. and $1501 \mathrm{~kg} . \mathrm{m} . / \mathrm{min}$. for $\mathbf{R}$ and $\mathbf{N}$ groups) were associated in both groups with decreases in cardiac output from the levels achieved at the previous work loads. Though one might consider that the normal subjects had approximated their peak exercise capacity with a mean pulse rate of 176 a minute, the same can 
certainly not be said for the athletes. This is attested to by their relatively low pulse rate of 145 a minute and their own estimation that they could easily have performed at a greater work load. The significance of this plateau in cardiac output at sub-maximal work levels is not apparent from this comparative study, but will be evaluated with progression to maximal exercise in a future investigation.

The sole statistically significant difference in stroke volume between groups $\mathbf{R}$ and $\mathbf{N}$ was found in the standing, resting position. Since the cardiac output was almost identical in the two groups, this stroke volume difference is explained entirely on the basis of a 35-beat-a-minute disparity in heart rate. At all other exercise levels, as well as resting recumbent, lower values for cardiac output and heart rate in the runners result in stroke volume values that are often considerably higher than but not significantly different from the normal subjects. These findings are comparable to those of Frick et al. (1963) comparing the trained and untrained states in supine subjects at rest and at a low work load.

Initiation of exercise was associated with marked increases in stroke volume above standing values. However, the level attained in both groups during horizontal walking equalled or was only slightly higher than that of recumbency. For the athletes, when each exercise grade is compared with the subsequent higher one, there is no significant stroke volume increase. There is, however, with augmented work loads, a gradual increment in stroke volume ultimately resulting in a 27 per cent increase in the mean above that observed during level treadmill walking. This peak stroke volume is also possibly significantly different from that for recumbency. Variations in stroke volume of this magnitude were not observed in the non-athletes. This discrepancy in stroke volume response to exercise is illustrated in Fig. 3 where comparison is again made with the corresponding groups of Bevegård et al. $(1960,1963)$. These results differ considerably from those of Musshoff et al. (1959a) who found

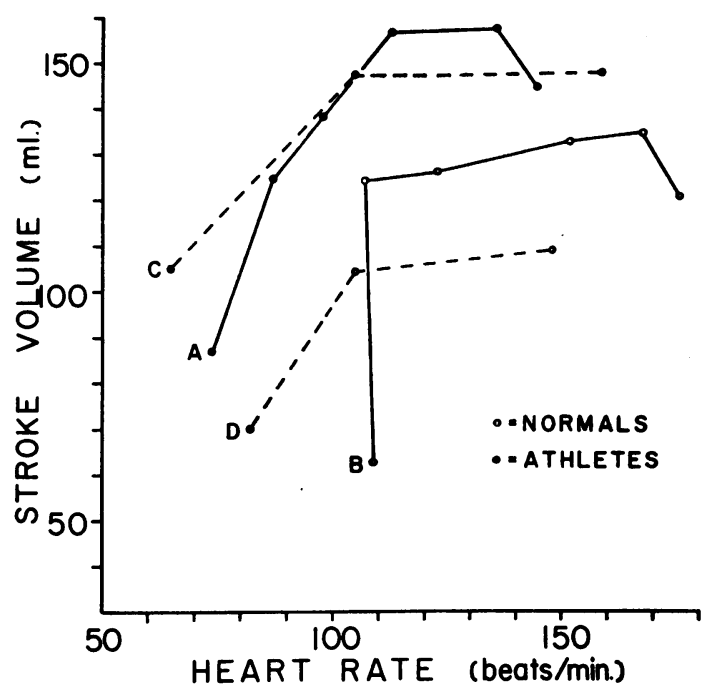

FIG. 3.-Mean stroke volume in relation to mean heart rate with subjects standing at rest and during progressively severe upright exercise. Plots A, B, $\mathrm{C}$, and $\mathrm{D}$ as in Fig. 1.

\section{0 and 39 per cent increases of stroke volume at}

peak exercise in athletes and non-athletes, respectively. It must be remembered, however, that these latter subjects performed all exercise in the supine position. The present data are also not entirely in accord with those of Bevegard et al. (1960) who found that the stroke volume associated with upright exercise in normal subjects was no higher than that supine at rest. The work loads utilized in this study were only $250-900 \mathrm{~kg} . \mathrm{m} . / \mathrm{min}$., however.

Comparison of left ventricular stroke work index provides a clear separation of the two groups. Whereas Group $\mathbf{N}$ maintains an almost constant index for all work loads, Group $\mathbf{R}$ exhibits a progressive augmentation of the index with each increase in work load, so that at the $14^{\circ}$ treadmill elevation stroke work was 36 per cent greater for the athletes. These differences are, of course, reflections of the larger stroke volume, and, at the higher levels, of higher mean arterial pressure in Group R. In relation to the data of Frick et al. (1963) for a work load of $400 \mathrm{~kg} . \mathrm{m} . / \mathrm{min}$., the present stroke work indices are considerably lower, but the mean arterial blood pressures in the former study appear unusually light for this work load.

It has been suggested (Cotes, 1963) that during moderate exercise the relation between ventilation and energy expenditure is the same for athletes and non-athletes. With greater energy expenditure, 


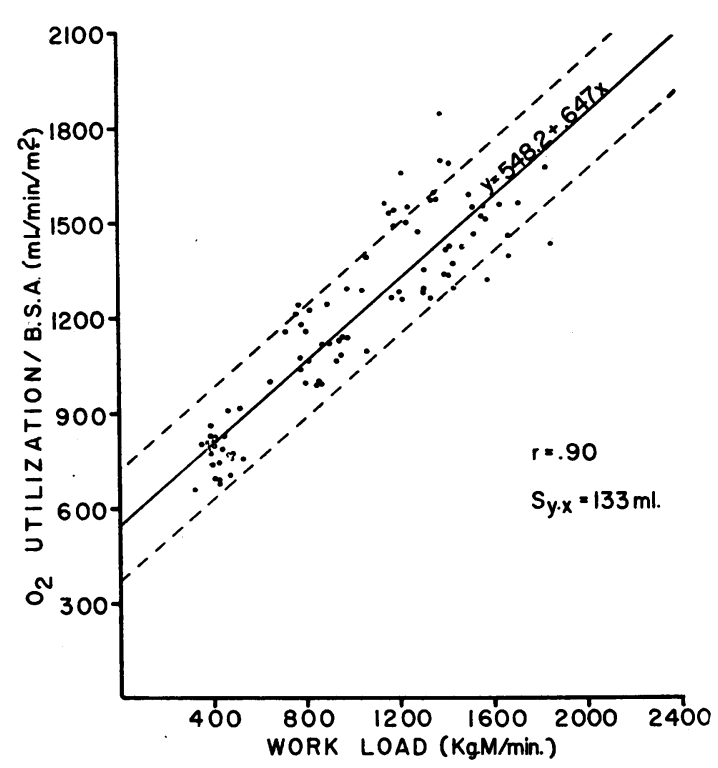

Fig. 4.-Oxygen utilization $/ \mathrm{m} .^{2}$ body surface area in relation to work load for non-athletes walking at treadmill inclinations of $4^{\circ}, 8^{\circ}, 12^{\circ}$, and $14^{\circ}$, $\mathrm{n}=91$. Broken lines represent \pm one standard error of the estimate.

however (above a minute volume of ventilation of $351 . /$ min.), the non-athlete exhibits a disproportionate increase in ventilation and departs from the previously linear relation. The present study does not bear this out. Although the runners evidenced increasingly lower ventilatory values than the "normals" as the severity of exercise increased, differences in minute volume of ventilation were not significant at any work load.

The question of differences in oxygen utilization between the trained and untrained state has often been discussed, and a general feeling seems to exist that the trained subject is more efficient and has a lower oxygen consumption for a given work load (Morehouse and Miller, 1963). Within the range of oxygen utilization observed in the present two groups $(300-3000 \mathrm{ml} / \mathrm{min}$. mean), this was certainly not the case, nor was it in the material of Musshoff et al. (1959a). The relation of oxygen utilization to work load, expressed as ml./kg.m. was almost identical in groups $\mathbf{R}$ and $\mathbf{N}$ over the exercise range employed. As seen in Fig. 4, where data are plotted for the normal subjects at the four

upper work loads, oxygen utilization bears a relatively constant linear relation to work load.

With regard to the "improved respiratory efficiency resulting from training" as evidenced by a lower oxygen ventilatory equivalent (litres ventilation/litre oxygen), we were once again unable to confirm any significant difference in the two groups. Fig. 5 illustrates that above a minute volume of ventilation of 32 litres, the runners do exhibit a greater oxygen utilization from a given minute volume and therefore a lower oxygen ventilatory equivalent. As seen from the standard error of the

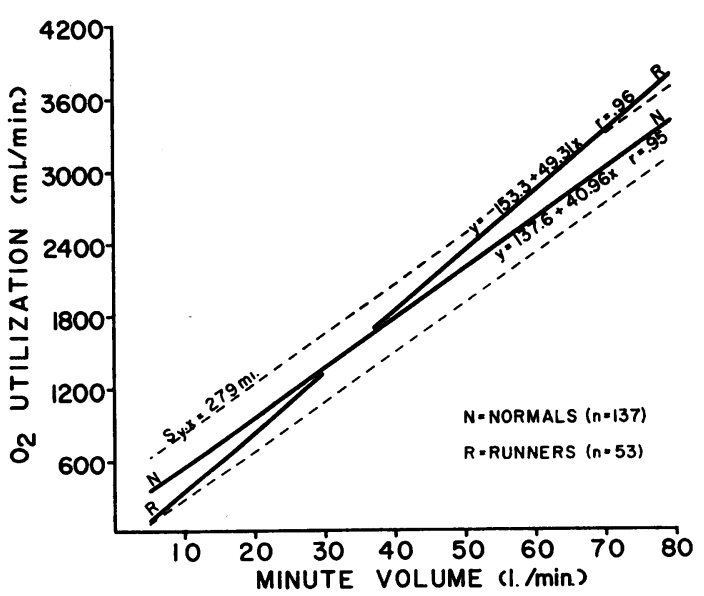

Fig. 5.-Correlation of oxygen utilization with minute volume of ventilation for athletes and non-athletes performing five levels of treadmill exercise. Broken lines represent \pm one standard error of the estimate for regression line $\mathbf{N}$. estimate plotted for the "normal" regression line, however, the group difference was statistically insignificant, even at the highest level of ventilation. In relating oxygen utilization to heart rate, the so-called "oxygen pulse", a clearcut differentiation of the two groups is obtained. Whether at rest or exercise the athletes consistently maintain a higher oxygen pulse, ranging from 12-28 per cent above the normals. These values for both groups agree very closely with those of Musshoff et al. (1959a).

An unexpected and most interesting finding in the present study is the lower carbon dioxide elimination exhibited by the athletes at all exercise levels. As seen in Fig. 6, this difference between groups becomes more pronounced with increasing minute volume of ventilation and is significant at the $4^{\circ}, 8^{\circ}, 12^{\circ}$, and $14^{\circ}$ treadmill in clinations, whether compared as mean carbon dioxide elimination or related to work load as 
ml./kg.m. Despite the fact that Group R also had lower oxygen utilization for all work loads, the difference in carbon dioxide elimination was so great that the respiratory quotient for the runners was considerably lower than for the normal subject, the greatest discrepancy occurring at the $8^{\circ}$ level with values of 0.64 and 0.81 . These variations are demonstrated in Fig. 7. To our knowledge, this phenomenon has received little attention in the published reports. In two studies attempting to measure an increase in work efficiency with training (McNelly, 1936; Knehr, Dill, and Neufeld, 1942) it is mentioned that the trained state is associated with a lower respiratory quotient than the untrained, but the finding is not discussed and an explanation is not attempted. The lower respiratory quotient of the athlete suggests to us that less carbohydrate katabolism is occurring at a given work load than in the non-athlete. Since it is known

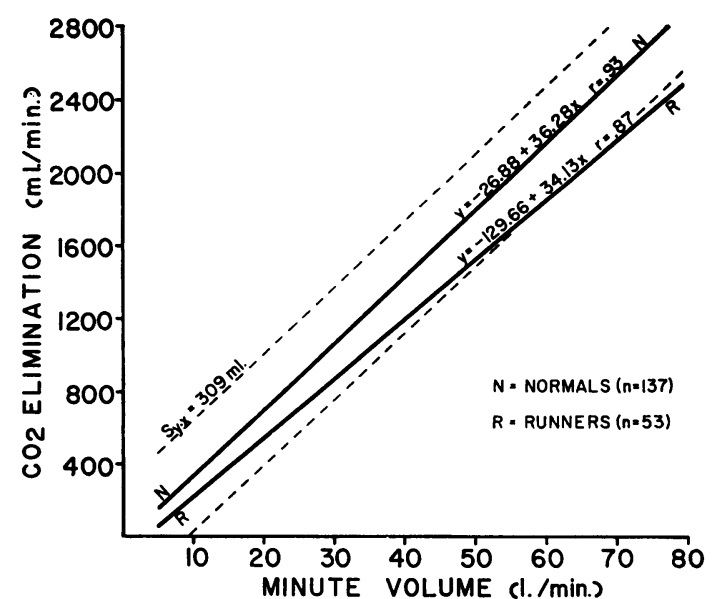

Fig. 6.-Correlation of carbon dioxide elimination with minute volume of ventilation for Groups $\mathbf{R}$ and $\mathbf{N}$ at five levels of treadmill exercise. \pm one standard error of the estimate for regression line $\mathrm{N}$ is represented by the broken lines.

that resting muscle relies more on fat metabolism than on carbohydrate, it seems plausible that trained muscle under conditions of moderate exercise may still retain some of the characteristics of the resting state. As the demands of exercise increase, a larger proportion of carbohydrate metabolism might be expected to occur accompanied by a rising respiratory quotient. The athletes do increase their respiratory quotient, but more slowly than the non-athlete in response to more work. Whether these changes are related to the lower blood lactate levels in athletes, signifying that they have been able to maintain aerobic metabolism for longer periods or at higher work loads, cannot be said at present.

Significant differences in systolic, diastolic, and mean blood pressures were not observed for Groups R and N. Likewise, values for peripheral vascular resistance were similar for the two groups at all exercise levels. The pressures recorded in the present subjects were considerably lower than those presented by Bevegård et al. (1963), and may represent differences in instrumentation, type of exercise, and use of the radial rather than brachial artery. Intravascular pressures were not found to increase with increasing work load as much as predicted by the regression equations of Holmgren (1956).

\section{SUMMARY}

A comparison of the circulatory and ventilatory responses to graded, upright exercise in 25 "normal" young men and 9 cross-country runners is presented. Apart from the consistently lower heart rates observed in the athletes at all exercise levels, strikingly few significant differences were observed between the two groups. Stroke volume, mean arterial blood pressure, and left ventricular stroke work index

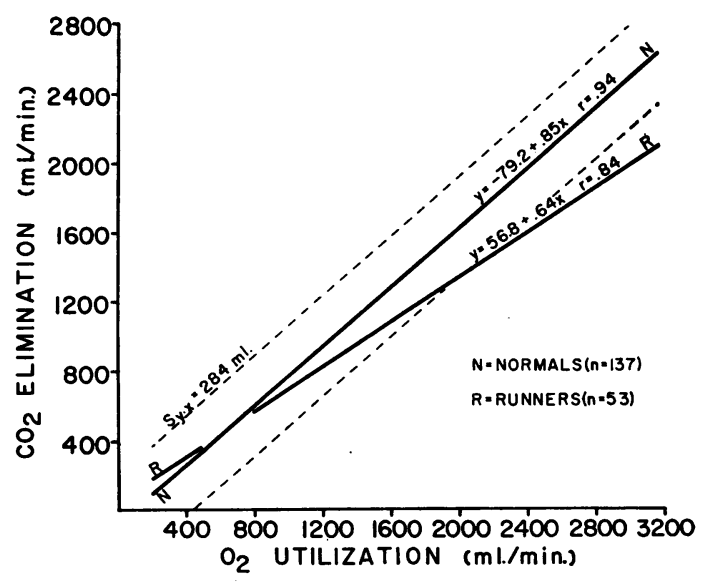

Fig. 7.-Correlation of carbon dioxide elimination with oxygen utilization during treadmill exercise. Broken lines represent \pm one standard error of the estimate calculated for the "normal" regression line. 
tended to be higher in the runners during exercise. The possible significance of a uniformly lower amount of carbon dioxide elimination by the runners is discussed.

\section{REFERENCES}

Åstrand, P-O. (1952). Experimental Studies of Physical Working Capacity in Relation to Sex and Age, pp. 1-171. E. Munksgaard, Copenhagen. (1956). Human physical fitness with special reference to sex and age. Physiol. Rev., 36, 307.

Bevegård, S. (1962). Studies on the regulation of the circulation in man. Acta physiol. scand., 57, Suppl. 200.

- Holmgren, A., and Jonsson, B. (1960). The effect of body position on the circulation at rest and during exercise, with special reference to the influence on stroke volume. Acta physiol. scand., 49, 279.

,-- , and - (1963). Circulatory studies in well trained athletes at rest and during heavy exercise, with special reference to stroke volume and the influence of body position. Acta physiol. scand., 57, 26.

Cobb, L. A., and Johnson, W. P. (1963). Hemodynamic relationship of anærobic metabolism and plasma free fatty acids during prolonged, strenuous exercise in trained and untrained subjects. J. clin. Invest., 42, 800.

Cotes, J. E. (1963). Exercise limitation in health and disease. Brit. med. Bull., 19, 31.

Freedman, M. E., Snider, G. L., Brostoff, P., Kimelblot, S., and Katz, L. N. (1955). Effects of training on response of cardiac output to muscular exercise in athletes. J. appl. Physiol., 8, 37.

Frick, M. H., Konttinen, A., and Sarajas, H. S. S. (1963). Effects of physical training on circulation at rest and during exercise. Amer. J. Cardiol., 12, 142.

Hanson, J. S., and Tabakin, B. S. (1964). Variation in simultaneous and rapidly-repeated cardiac output determinations by dye-dilution method. J. appl. Physiol., 19, 275.

Harvey, R. M., Smith, W. M., Parker, J. O., and Ferrer, M. I. (1962). The response of the abnormal heart to exercise. Circulation, 26, 341.

Holmgren, A. (1956). Circulatory changes during muscular work in man. Scand. J. clin. Lab. Invest., 8, Suppl. 24.

- Jonsson, B., and Sjöstrand, T. (1960a). Circulatory data in normal subjects at rest and during exercise in recumbent position, with special reference to the stroke volume at different work intensities. Acta physiol. scand., 49, 343.

- Mossfeldt, F., Sjöstrand, T., and Ström, G. (1960b). Effect of training on work capacity, total hemoglobin, blood volume, heart volume and pulse rate in recumbent and upright positions. Acta physiol. scand., 50, 72.

Jongbloed, J. (1962). Observations on training-effects. Arch. int. Pharmacodyn., 139, 535.

Knehr, C. A., Dill, D. B., and Neufeld, W. (1942). Training and its effects on man at rest and at work. Amer. J. Physiol., 136, 148.

McNelly, W. C. (1936). Some effects of training on the respiratory response to exercise (abstract). Amer. $J$. Physiol., 116, 100 .

Morehouse, L. E., and Miller, A. T., Jr. (1963). Physiology of Exercise, p. 257. C. V. Mosby, St. Louis.

Musshoff, K., Reindell, H., and Klepzig, H. (1959a). Stroke volume, arterio-venous difference, cardiac output and physical working capacity, and their relationship to heart volume. Acta cardiol. (Brux.), 14, 427.

-, , Steim, H., and König. K. (1959b). Die Sauerstoffaufnahme pro Herzchlag $\left(\mathrm{O}_{2}-\mathrm{Puls}\right)$ als Funktion des Schlagvolumens, der arteriovenösen Differenz, des Minutenvolumens und des Herzvolumens. Z. Kreisl.Forsch., 48, 255

Tabakin, B. S., Hanson, J. S., and Levy, A. M. (1965). Effects of physical training on the cardiovascular and respiratory response to graded upright exercise in distance runners. Brit. Heart J., 27, 205.

$-, \frac{\text { Merriam, T. W., and Caldwell, E. J. (1964). Hemodynamic response of normal men to graded treadmill }}{-}$ exercise. J. appl. Physiol., 19, 457.

Wang, Y., Marshall, R. J., and Shepherd, J. T. (1960). The effect of changes in posture and of graded exercise on stroke volume in man. J. clin. Invest., 39, 1051.

-, Rowell, L. B., Blomqvist, G., and Taylor, H. L. (1965). The effects of a conditioning program on the cardiovascular function in exercise of sedentary college males. J. appl. Physiol. To be published.

- Shepherd, J. T., Marshall, R. J., Rowell, L., and Taylor, H. L. (1961). Cardiac response to exercise in unconditioned young men and in athletes (abstract). Circulation, 24, 1064. 